\begin{tabular}{|c|c|}
\hline \multirow{3}{*}{ 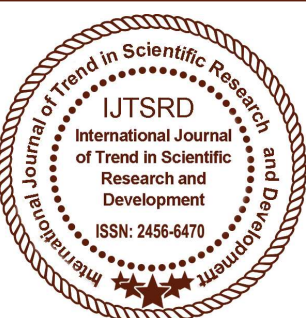 } & $\begin{array}{l}\text { International Journal of Trend in Scientific } \\
\text { Research and Development (IJTSRD) }\end{array}$ \\
\hline & Access Journal \\
\hline & ISSN No: 2456 - 6470 | www.ijtsrd.com | Volume - 2 | Issue -3 \\
\hline
\end{tabular}

\title{
Grid connected PV systems and their growth in power system
}

\author{
Javeed Ahmad Khan \\ M.Tech Scholar, Electrical Engineering Department \\ YIET, Gadhauli, Yamunanagar, Haryana, India
}

\section{ABSTRACT}

Uneconomical extension of the grid has led to generation of electric power at the end user facility and has been proved to be cost effective and to an extent efficient. With augmented significance on ecofriendly technologies the use of renewable energy sources such as micro-hydro, wind, solar, biomass and biogas is being explored. This paper presents an addresses the potential impacts of grid-connected photovoltaic (PV) systems on electrical networks. The paper starts by emphasizing the increased importance of generating electricity from PV arrays. The growth in PV installed capacity worldwide is elaborated; futuristic expansion plans for several countries as well as existing PV projects worldwide are highlighted. The paper continues by evaluating the most important impacts of PV electricity on electrical networks. Finally, the authors summarize the literature's findings regarding the maximum allowable PV penetration that can be safely integrated into existing networks.

\section{INTRODUCTION}

Requirement of energy in its most suitable form is the need of millions of people throughout the globe. It can be fuel, used in transportation, electrical energy for lighting loads, etc. With the beginning of 21 st century, industrialization has raised many folds compared to 18th century; this has resulted in a massive scale extraction of fossil fuels at an alarming pace globally. The global climate change has added to the problem of scarcity of fossil fuels. Now it is time to look into the solution of energy crisis, created by the reduction of fossil fuels without altering the climate behavior. In stand-alone mode, transportation of conventional energy sources (like coal, oil, and natural gas) is quite difficult and grid extension is also not cost effective due to remoteness and difficult terrain. Renewable energy is the most appropriate solution to supply energy in isolated areas. Utilization of locally available resources is the best possible option to meet the energy requirement. Depending on the site conditions, single technology or aggregated technology would be selected in stand-alone mode.

These ambitious targets of reducing dependency on fossil fuels - and hence, decreasing the resulting greenhouse gas emissions - cannot be achieved without active participation by the global energy sector, which is responsible for approximately two third the world's greenhouse gas emissions. However, this task is made difficult by the booming demand for electricity: electrical energy currently represents $12 \%$ of total global energy consumption; however, this percentage is expected to increase in the future to become $34 \%$ of total consumed energy by 2025 . Thus, a complex dilemma exists: on one hand, greenhouse emissions produced by the energy sector require significant reduction; on the other hand, electrical energy production must increase to meet growing demand for electricity. In the Canadian energy sector, the situation is even worse as coal is extensively used for the generation of electricity; approximately $17 \%$ of the total electricity generated in Canada is obtained by coal fired power plants. Coal is one of the biggest sources of greenhouse gases. Utilizing renewable sources of energy such as wind and solar to generate electricity provides a feasible solution for the previous dilemma as these renewables are clean, emission-free sources of energy that can be used to generate electricity and at the same time protect our environment for future generations. Solar energy, in 
particular, if properly utilized to generate electricity using photovoltaic (PV) arrays, can fulfill all the electricity needs of mankind. A simple calculation reveals that the amount of solar energy received in 1 hour by the earth is equivalent to the world's annual energy consumption. Another calculation shows that all the energy demand of the United States can be supplied by only $0.2 \%$ of the solar radiation it receives.

It was believed that integrating PV solar systems into power networks would not be a difficult task; however, when the penetration level of PV electricity started to increase, utilities began to face new nontraditional problems mainly due to the intermittent nature of solar energy; PV array output is highly dependent on environmental conditions such as temperature and irradiance. Fast moving clouds, for example, result in rapid fluctuations in the output power of PV arrays, and thus, the power system has to deal with not only uncontrollable demand but also uncontrollable generation. In this paper, the impacts of solar PV arrays on electrical systems are reviewed to identify the bottlenecks blocking the widespread adoption of PV electricity.

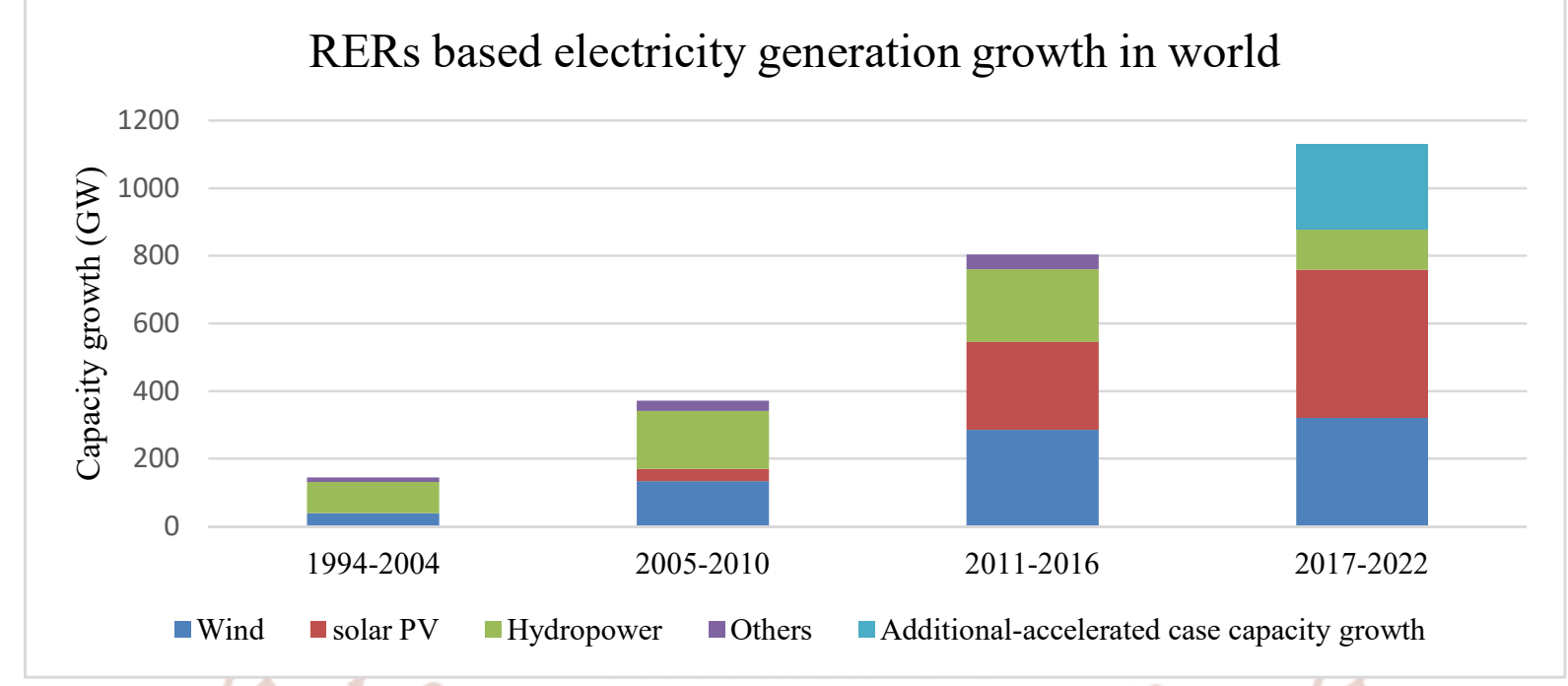

Fig. 1: Rise in RERS based electricity generation worldwide

\section{GROWTH IN THE PV ELECTRICITY INSTALLED CAPACITY}

The global PV installed capacity has increased greatly over the past few decades. During the past 15 years, global PV installed capacity has experienced an annual growth rate of about $45 \%$ as shown in Figure 1. This is because the global energy sector realized that generating electricity from renewables will be the only available option to satisfy the growing demand for electricity when all available fossil fuel resources are consumed. Another reason for that is the anticipated benefit of PV electricity sector on national economy. Despite its high initial cost (6000-10 $000 \$ / \mathrm{kW}$ ), cost of jobs created by PV electricity is 46 times less than the cost of jobs created by nuclear, natural gas, or coal. A million dollar investment in solar PV will create only $30 \%-42 \%$ of the energy produced by other power plants but 2.4-6.4 times more jobs. Thus, many countries have developed ambitious plans to increase their electricity production using PV arrays; for example, in Ontario, the FIT and the microFIT programs funded by the Ontario Power
Authority (OPA) are intended to encourage the development of renewables in the province by offering competitive incentives. This initiative is conceptually important as $80 \%$ of the existing electric generation capacity in Ontario needs to be replaced within the next $20 \mathrm{yr}$. Most of the MicroFIT proposals are rooftop PV systems. As a result, annual PV installations in Canada are expected to exceed the annual wind installations by 2013 and there would be $3 \mathrm{GW}$ of solar energy in Ontario electric system by 2015. In California, the Renewable Portfolio standard (RPS) program submitted by governor Arnold Schwarzenegger requires thatthe penetration level of renewables reaches the $33 \%$ goal by 2020 ; more than $9500 \mathrm{MW}$ of PV power projects are currently proposed for interconnection with the system by 2018 . In China, the Government has developed ambitious plans to install $10 \mathrm{GW}$ PV capacities. The government also targets $50 \mathrm{GW}$ total installed PV capacity by 2020.13 In July 2009, the Indian Government unveiled a 19109 US\$ plan to produce $20 \mathrm{GW}$ of solar power by 2020.14 In Germany, the installation rate of solar PV systems increased from $800 \mathrm{MW} /$ year 
in 2005 to $2.2 \mathrm{GW} /$ year in 2017. Moreover, the German political establishment has agreed to raise the solar PV installation target to $2.5-3.5 \mathrm{GW} / \mathrm{yr}$ starting from 2011.Electricity from solar PV and concentrated solar power plants is significantly expensive and requires significant drop in cost or change in policies by either subsidizing or forcing the use of these technologies to be able to achieve significant market penetration.

\section{IMPACTS OF GRID-CONNECTED PV ELECTRICITY ON POWER SYSTEMS}

In general, grid-connected PV systems are installed to enhance the performance of the electric network; PV arrays (as well as other distributed generation (DG) units) provide energy at the load side of the distribution network, reducing the feeder active power loading and hence improving the voltage profile. As a result, PV systems can delay the operation time of shunt capacitors and series voltage regulators, thus increasing their lifetime. PV systems can also reduce the losses in distribution feeders if optimally sized and allocated. The example given in Ref. 25 shows that for a distribution feeder supplying $10 \mathrm{MW}$ uniformly distributed load along its length, 4-6 MW of PV distributed generation will provide optimal minimum losses in the feeder. PV systems can increase the load carrying capability (LCC), which is the amount of load a power system can handle while satisfying certain reliability criteria, of existing networks. To meet increased demand while satisfying the same reliability criteria, utilities have to increase their generation capacity. However, in Ref. 26, it was shown that the LCC of an electrical network can be doubled with $10 \%$ PV penetration level; thus, utilities can defer the addition of extra generating capacities to other areas. The LCC can be increased further more if battery storage systems are installed in parallel with PV arrays.

However, PV systems can also impose several negative impacts on power networks, especially if their penetration level is high. These impacts are dependent on the size as well as the location of the PV system. According to the IEEE standard 929-2000, PV systems are classified based on their ratings into three distinct categories: (1) Small systems rated at 10 $\mathrm{kW}$ or less, (2) intermediate systems rated between 10 $\mathrm{kW}$ and $500 \mathrm{~kW}$, and (3) large systems rated above $500 \mathrm{~kW}$. The first two categories are usually installed at the distribution level, as opposed to the last category which is usually installed at the transmission/sub-transmission levels.
A. Impacts of large PV systems This section reviews the literature concerning the anticipated impacts of large-scale PV systems (above $500 \mathrm{~kW}$ ) on transmission/sub-transmission networks.

PV arrays' output is unpredictable and is highly dependent on environmental conditions such as temperature and insolation levels as depicted in Figures 2 and 3, respectively. Partial shading due to passing clouds, temperature, and insolation random variations are all factors that will affect PV system production, resulting in rapid fluctuations in its output power.

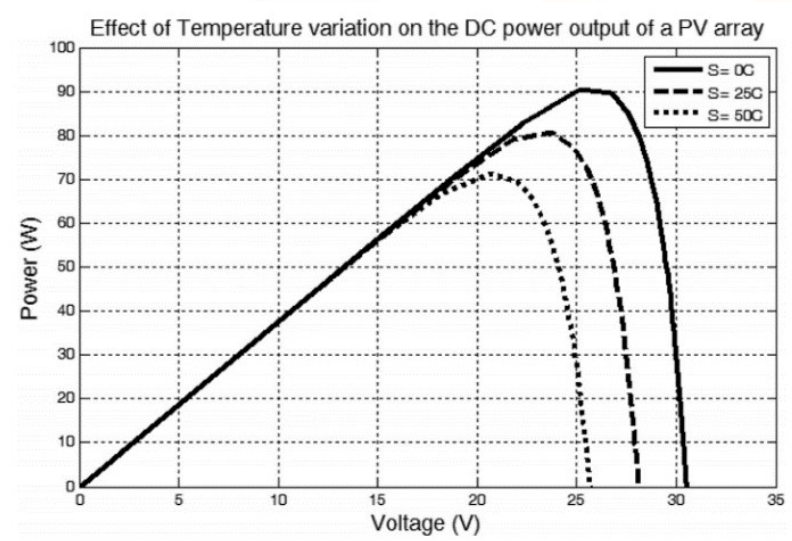

Fig. 2. Effect of temperature variation on the DC power of a PV array.

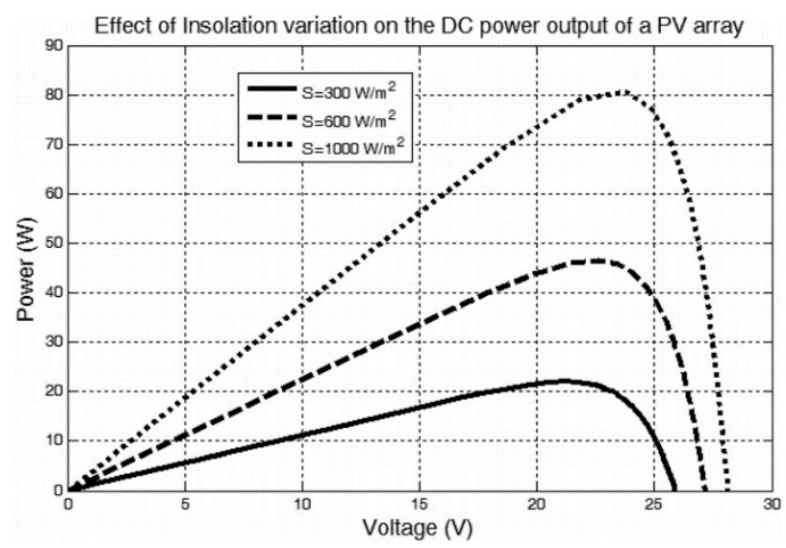

Fig. 3. Effect of insolation variation on the DC power output of a PV array

In a practical study [25] on a $2 \mathrm{MW}$ solar plant on a distribution feeder, the power output was measured and recorded every $5 \mathrm{~min}$. The measurements showed sudden and severe power fluctuations caused by passing clouds and morning fog. Active power fluctuations result in severe frequency variations in the electrical network, whereas reactive power fluctuations result in substantial voltage fluctuations. These voltage fluctuations may cause nuisance switching of capacitor banks. In Ref. 28, it has also been shown that voltage flickers occur more 
frequently at higher penetration of PV systems during clouds transients.

\section{B. Increased ancillary services requirements}

Since the grid acts as an energy buffer to compensate for any power fluctuations and firm up the output power of PV sources, thus, generating stations' outputs need to be adjusted frequently to cope with the PV power fluctuations, i.e., to dance with the sun. For example, if a cloud blanked out a PV system supplying $1 \mathrm{MW}$ of electricity in $10 \mathrm{~s}$, then the electric grid should be able to inject extra power at a rate of $1 \mathrm{MW} / 10 \mathrm{~s}$ or else voltage and frequency disturbances will occur in the power system. As a result, utilities need to incorporate fast ramping power generation to compensate for these power fluctuations from PV arrays before voltage and frequency variations exceed the allowable limits. Current regulating generation sources (such as hydrogenerator plants) are too slow and so are unable to compensate for the abovementioned fast power fluctuations. They also produce too much pollution during ramping regulating operations. Therefore, the increase in regulation service requirements counteracts the emission savings resulting from renewable generation. The previous situation also necessitates a significant increase in the frequency regulation requirements at higher penetration levels of PV systems. For example, the current frequency regulation requirements at the California Independent System Operator (CAISO) are 1\% of peak demand, or about $350 \mathrm{MW}$. It has been estimated that $2 \%$ frequency regulation requirement will be required for a penetration level of $20 \% \mathrm{PV}$ electricity and $4 \%$ to integrate $33 \%$ PV electricity by 2022 . Another study, performed in Japan, concluded that for $10 \% \mathrm{PV}$ penetration, the frequency regulation requirements will increase $2.5 \%$ over the base no-PV case. At $30 \%$ solar PV penetration, authors found that that frequency regulation should increase by $10 \%$. According to their conclusion, the cost of doing that will exceed any possible benefits from PV electricity. A similar study in Arizona32 concluded that the maximum tolerable penetration level of PV systems is approximately $5 \%$ with the existing frequency regulation capacities. For the above mentioned reason, frequency regulation service plays an important role in determining the maximum allowable penetration level of PV electricity in the power system.

Geographical distribution of PV arrays in a certain region plays an important role in determining the maximum allowable PV penetration in that region; the closer those PV arrays are, the more power fluctuations are expected due to clouds, and the more frequency regulation service is needed to balance out those power fluctuations. Jewell studied this phenomenon in Ref. 7 and concluded for the current spinning reserve capacities, the following penetration levels are acceptable:

- $1.3 \%$ if the PV system is located at a central station.

- $6.3 \%$ if the PV system is located in $10 \mathrm{~km}^{2}$ area.

- $18.1 \%$ if the PV system is located in $100 \mathrm{~km}^{2}$ area.

- $35.8 \%$ if the PV system is located in $1000 \mathrm{~km}^{2}$ area.

These results indicate that, due to their dispersed nature, small-scale PV systems are not likely to impact frequency regulation requirements and so, these requirements should be determined based on the penetration level of large, centralized PV stations only.

\section{STABILITY PROBLEMS}

As explained earlier, PV arrays' output is unpredictable and is highly dependent on environmental conditions. This unpredictability greatly impacts the power system operation as they cannot provide a dispatchable supply that is adjustable to the varying demand, and thus the power system has to deal with not only uncontrollable demand but also uncontrollable generation. 27 As a result, greater load stability problems may occur. PV arrays do not have any rotating masses; thus, they do not have inertia and their dynamic behavior is completely controlled by the characteristics of the interfacing inverter. In Ref. 33 , the impact of high penetration of PV generation on power system small signal stability was addressed. The paper showed that PV systems may have beneficial or detrimental impacts on the power system stability depending on their locations, ratings, etc. As the penetration level of PV increases, more conventional generators are being replaced by PV arrays; thus, the damping ratio of the system increases. As a result, the oscillation in the system decreases. The presence of solar PV generation also can change the mode shape of the inter-area mode for the synchronous generators those are not replaced by PV systems. The authors found that some critical synchronous generators should be kept online (even if they are operating beyond their economic operating range) to maintain sufficient damping of the system. Another study34 showed that during fault conditions 
in a system with high PV penetration, rotors of some of the conventional generators swing at higher magnitudes. The authors of Ref. 35 studied the impacts of large-scale PVs on voltage stability of subtransmission systems. The study concluded that PV sizes, locations, and modes of operation have strong impacts on static voltage stability; voltage stability deteriorates due to PV inverters operating in constant power factor mode of operation, whereas PV inverters operating in the voltage regulation mode may improve the system voltage stability.

\section{POWER QUALITY PROBLEMS}

At coupled ac topologies the ac network of the microgrid is directly connected to the power grid by a transformer and an ac-dc converter is used for the dc network. Alternatively, decoupled ac configurations are composed at least by an ac-dc and dc-ac stage; this means there is no direct connection between the power grid and the ac network of the microgrid. Fig. 3 shows the most important configurations identified for both topologPower quality issues are one of the major impacts of high PV penetration on distribution networks; power inverters used to interface PV arrays to power grids are producing harmonic currents; thus, they may increase the total harmonic distortion (THD) of both voltage and currents at the point of common coupling (PCC). However, voltage harmonics are usually within limits if the network is stiff enough with low equivalent series impedance.41 Current harmonics, on the other hand, are produced by high pulse power electronic inverters and usually appear at high orders with small magnitudes.19 An issue with higher-order current harmonics is that they may trigger resonance in the system at high frequencies. This situation occurred in the holiday park "Bronsbergen" in the Netherlands where the 11th and 15 th voltage harmonics exceeded the permissible limits due to resonance between the grid inductance and the inverter high capacitance.21 Diversity effect between different current harmonics can also reduce the overall magnitude of those current harmonics; nevertheless, in Ref. 42, it is reported that the phase shift for single phase inverters is usually small, and thus these harmonic currents added to each other, resulting in a total increase in the current THD which may lead to nuisance between inverters. This condition was observed in the Nieuwland project in the Netherlands; although each inverter complies with the Dutch power quality standards, measurements taken at the PCC showed a high current harmonic pollution level, which violates the Dutch power quality standards due to interaction between the harmonics of different inverters.22 Another power quality concern is the inter-harmonics that appear at low harmonic range (below the 13th harmonic). These inter-harmonics may interact with loads in the vicinity of the inverter.43 Even harmonics (especially the second harmonics) can possibly add to the unwanted negative sequence currents affecting three phase loads.29 DC injections as well may accumulate and flow through distribution transformer, leading to a possible damage.29 IEEE Std. 1547 restricts DC injection from a PV system to $0.5 \%$.

\section{INCREASED REACTIVE POWER REQUIREMENTS}

PV inverters normally operate at unity power factor for two reasons. The first reason is that current standards (IEEE 929-2000) do not allow PV inverters to operate in the voltage regulation mode. The second reason is that owners of small residential PV systems in the incentive-programs are revenued only for their kilowatt-hour yield, not for their kilovolt-ampere hour production. Thus, they prefer to operate their inverters at unity power factor to maximize the active power generated and accordingly, their return. As a result, the active power requirements of existing loads are partially met by PV systems, reducing the active power supply from the utility. However, reactive power requirements are still the same and have to be supplied completely by the utility. A high rate of reactive power supply is not preferred by the utilities19 because in this case distribution transformers will operate at very low power factor (in some cases it can reach 0.6). Transformers' efficiency decreases as their operating power factor decreases, as a result, the overall losses in distribution transformers will increase reducing the overall system efficiency.

\section{CONCLUSIONS}

PV solar systems are expected to be one of the most growing sources of electricity in the next decades. However, they have numerous negative impacts on electrical networks. There is no agreed upon maximum allowable penetration limit for PV electricity in a certain network as it depends on the network's characteristics as well as types, locations, and geographical distribution of PV arrays within the network. However, cloud transients and the mandatory increase in frequency regulation services are usually the bottleneck against the widespread adoption of PV electricity. It is not exaggeratory to 
say that electrical power systems under the current circumstances are not yet ready to accommodate the anticipated increase in PV penetration. More research work is clearly required to address these impacts and hence, stretch the allowable limits of PV electricity.

\section{REFERENCES}

1. Ramakumar R. Integrated renewable energy systems: power engineeringreview. IEEE 1995;15(2):10-3.

2. Ramakumar R, Abouzahr I, Ashenay KA. Knowledge-based approach to thedesign of integrated renewable energy systems. IEEE Trans Energy Convers1995;10:736-46.

3. Ramakumar R, Shetty PS, Ashenayi K. A linear programming approach to thedesign of integrated renewable energy systems for developing countries.IEEE Trans Energy Convers 1986;EC$1: 18-24$.

4. Kanase Patil AB, Saini RP, Sharma MP. Integrated renewable energy systemsfor off grid rural electrification of remote area. Renew Energy 2013;5:1342-9.

5. Ashenayi K, Ramakumar R. IRES a program to design integrated renewableenergy systems. Energy 1990;15:1143-52.

6. Ramakumar R, Abouzahr I, Krishnan K, Ashenayi K. Design scenarios for integrated renewable energy systems. IEEE Trans Energy Convers 1995;10: 736-46.

7. Lasseter R, Abbas A, Marnay C, Stevens J, Dagle $\mathrm{J}$, Guttromson R, et al. Integration of distributed energy resources: the CERTS Microgrid Concept California Energy Commission. P500-03-089F; October 2003.

8. Farret FA, Simões MG. Integration of Alternative Sources of Energy. Hoboken,NJ: Wiley; 2006.

9. Sao CK, Lehn PW. A transformerless energy storage system based on acascade multilevel PWM converter with star configuration. IEEE Trans IndAppl 2008;44(5):1621-30.

10. Sood PK, Lipo TA, Hansen IG. A versatile power converter for high-frequencylink systems. IEEE Trans Power Electron 1988;3(4):383-90.

11. Barton JP, Infield DG. Energy storage and its use with intermittent renewableenergy. IEEE Trans Energy Convers 2004;19:441-8.
12. Makansi J, Abboud A. Energy storage. The missing link in the electricity valuechain. Saint Louis, USA: Energy Storage Council; 2002.

13. Abbey C, Robinson J, Joós G. Integrating renewable energy sources andstorage into isolated diesel generator supplied electric power systems. In:Proceedings of the 13th international power electronics and motion controlconference (EPEPEMC); 2008.

14. Chen H, Cong TN, Yang W, Tan C, Li Y, Ding Y. Progress in electrical energystorage system: a critical review. Prog Nat Sci 2009;19:291-312.

15. Karpinski AP, Makovetski B, Russell SJ, Serenyi JR, Williams DC. Silver-zinc:status of technology and applications. J Power Sources 1999;80:53-60.

16. Moore T, Douglas J. Energy storage, big opportunities on a smaller scale. EPRIJ 2006;Spring Issue:16-23.

17. Rahman F, Rehman S, Arif M, Majeed A. Overview of energy storage systemsfor storing electricity from renewable energy sources in Saudi Arabia. RenewSustain Energy Rev 2012;16:27483.

18. Rahman F, Skyllas-Kazacos M. Solubility of vanadyl sulfate in concentratedsulfuric acid solutions. J Power Sources 1998;72:105-10.

19. F. Katiraei, K. Mauch, and L. Dignard-Bailey, "Integration of photovoltaic power systems in high-penetration clusters for distribution networks and mini-grids," National Resources Canada, January 2009

20. Schainker RB. Executive overview: energy storage options for a sustainableenergy future. In: Proceedings of the Power Engineering Society generalmeeting, vol. 2: 2004. p. 2309-14.

21. Chauhan A, Saini RP. Statistical analysis of wind speed data using Weibulldistribution parameters. In: Proceedings of the 1st International Conferenceon Non Conventional Energy (ICONCE), vol. 1: 2014. p. 160-3.

22. Khatod DK, Pant V, Sharma J. Analytical approach for well-being assessmentof small autonomous power systems with solar and wind energy sources.IEEE Trans Energy Convers 2010;25:535-45.

23. 3B. Mather, "Analysis of high-penetration levels of PV into the distribution grid in California," in 
High Penetration Solar Forum, U.S. Department of Energy, March 2011

24. Kanase Patil AB, Saini RP, Sharma MP. Development of IREOM model basedon seasonally varying load profile for hilly remote areas of Uttarakhand statein India. Energy 2011;36:5690-702.

25. J. H. R. Enslin, "Network impacts of high penetration of photovoltaic solar power systems," in 2010 IEEE Power and Energy Society General Meeting (2010), pp. 1-5.

26. J. T. Day and W. J. Hobbs, "Reliability impact of solar electric generation upon electric utility systems," IEEE Trans. Reliab. R-31, 304-307 (1982).

27. R. Yan and T. K. Saha, "Voltage variation sensitivity analysis for unbalanced distribution networks due to photovoltaic power fluctuations," IEEE Transactions on Power Systems 27, 10781089 (2012).

28. See

http:/www.ece.cmu.edu/electriconf/pdfs/Navigant $\% 20-$

$\% 20$ Integrating $\% 20 \mathrm{PV} \% 20 \mathrm{on} \% 20$ Distribution $\% 2$

0- $\quad \% 20 \mathrm{CMU} \% 20$ Electricity $\% 20$ Industry $\% 20$ -

\%2003-09-2011.pdf for effect of PV systems on system voltages.

29. F. A. Farret and M. G. Sim oes, Integration of Alternative Sources of Energy (Wiley Online Library, 2006).

30. J. Enslin, "Grid impacts and solutions of renewables at high penetration levels," Quanta Technology, 2009 